\title{
THE ARMORY CHAMBER AND ARMED FORCES OF RUSSIA IN THE SECOND HALF OF 17TH - EARLY 18TH CENTURY
}

\author{
Sergey P. Orlenko \\ Candidate of Sciences (History), Leading Researcher, \\ Moscow Kremlin State Historical and Cultural Museum and Heritage Site \\ orlenko@kremlin.museum.ru \\ Kremlin, 103132 Moscow, Russian Federation
}

\begin{abstract}
The article is devoted to the insufficiently studied aspect of the activities of the Armory chamber in the second half of 17th - beginning of 18th centuries - supplying the needs of the Russian armed forces.

Political and military realities of the first half of the seventeenth century revealed the need for the modernization and transformation of the armed forces of Russia. Military reform required a massive amount of combat weapons and equipment made by Western European standard. The middle of the 17th century was the times of a search for an optimal algorithm which would provide the armed forces with weapons and equipment. The integration in this process of the court gunsmith and Armory was an effective solution. The content of the Inventory of the Armory Chamber in 1647 can be divided into two parts: 1) parade and ceremonial weapons and armor, designed for the sovereign and court 2) a huge number of combat weapons deposed in a different storages.

The research is based on the complex of archival documents showing the role of the Armory chamber officials in organizing the purchase of combat weapons, its testing, preserving, repairing and transfer to the troops. The author also observed the changes in the activities of the institution in the last quarter of the century - when craftspeople of the court Armory workshop participated in the manufacturing of some special types of combat arms and service as a military gunsmith directly in troops and provincial armories.

Key words: Armoury Chamber, 17th century, arsenal, armed forces, procurement of weapons, manufacture of weapons.

УДК 94(045)(470-25)

ББК $63.3(2) 45$

Дата поступления статьи: 25.01.2016

Дата принятия статьи: 29.02.2016
\end{abstract}

\section{ОРУЖЕЙНАЯ ПАЛАТА И ВООРУЖЕННЫЕ СИЛЫ РОССИИ ВО ВТОРОЙ ПОЛОВИНЕ ХVII - НАЧАЛЕ ХVII в. ${ }^{1}$}

\author{
Сергей Павлович Орленко \\ Кандидат исторических наук, ведущий научный сотрудник, \\ ФГБУК «Государственный историко-культурный музей-заповедник “Московский Кремль”» \\ orlenko@kremlin.museum.ru \\ Кремль, 103132 г. Москва, Российская Федерация
}

Аннотация. Статья посвящена малоизученной стороне деятельности Оружейной палаты во второй половине XVII - начале XVIII в. - обеспечению потребностей вооруженных сил России. На основании изучения комплекса архивных документов показана роль должностных лиц Оружейной палаты в организац ции поставок строевого оружия, его проверки, хранения и выдаче в войска. Отмечены изменения деятельности ведомства в последней четверти столетия - участие мастеров Оружейной палаты в изготовлении строевого оружия и служба в качестве войсковых оружейников.

Ключевые слова: Оружейная палата, XVII век, арсенал, вооруженные силы, закупка оружия, производство оружия. 


\section{ОТЕЧЕСТВЕННАЯ ИСТОРИЯ}

Исторически устоявшимся считается мнение, что в XVII столетии Оружейная палата представляла собой придворную мастерскую и хранилище государевой оружейной казны. Ряд работ содержит упоминания об Оружейной палате как об одном из основных арсеналов русского государства [3, с. 8-37; 4, с. 173-181]. Военно-политические реалии первой половины XVII столетия выявили необходимость преобразования вооруженных сил России. Неудача Смоленской кампании 1632 1634 гг. показала необходимость качественного роста подготовленности командного состава, увеличения числа солдатских и рейтарских полков. Военная реформа требовала колоссального количества строевого оружия и снаряжения западноевропейского образца.

Содержание Перечневой росписи оружия, хранящегося в Оружейной палате в 1647 г., можно условно разделить на две части: 1) парадное, церемониальное оружие и доспехи, предназначенные для самого государя и придворных чинов [7, л. 1-37]; 2) огромное количество строевого оружия, распределенного по различным хранилищам. Опись фиксирует тысячи пистолетов, карабинов и мушкетов с замками разных типов, сабель и шпаг, пик, шлемов, лат и пр. «Да в розных полатах всякого розхожего ружья и ратной збруи»: различные предметы воинского снаряжения (солдатские лядунки и бандельеры, мушкетные подсошки, ключи для колесных замков и т. д.), а также всевозможные детали оружия и оружейные полуфабрикаты (мушкетные, карабинные и пистолетные стволы и замки, карабинные скобы и «деревья станочные»- заготовки ружейных лож) [7, л. 37-80].

Роль Оружейной палаты в вопросах обеспечения вооруженных сил не ограничивалась лишь хранением строевого оружия и снаряжения. Заключением сделок - «уговоров» на поставку в Россию значительной части строевого оружия - занимались чины, возглавлявшие Оружейную палату. В частности, Опись содержит перечисление «ружья и ратной сбруи, что принята в Оружейной приказ по уговору боярина князя Бориса Александровича Репнина со 147 (1638/39) и по нынешней по 155-й (1647) год у иноземцов, и что прислано ис приказов, принятой в хранилища Оружейной палаты»[7, л. 76-76].
Очевидно, что поступление, хранение и выдача больших объемов строевого оружия требовали правильной организации и учета. Кроме того, поступавшее на хранение оружие нуждалось в проверке на безопасность использования, а также в проведении рутинных работ по чистке и мелкому ремонту.

Как следует из содержания описи 1647 г., администрации Оружейной палаты удалось организовать решение этих задач. Документ включает в себя упоминание о необходимости «доимки на иноземце на Петре Марселисе вместо рваных 199 стволов». Кроме того, из общего числа поставленных иноземцем доспехов было выбрано 120 лат, что «стрельбою неопытываны» [7, л. 77-79]. Решение комплекса задач по приему, хранению и выдаче оружия из Оружейной палаты требовало участия подготовленных кадров - ответственных должностных лиц. После ряда проб и экспериментов в 1630-1640-е гг. руководством Оружейного приказа был найдено оптимальное кадровое решение этого вопроса. Возник институт «Оружейной палаты дозорщиков». Можно предположить, что назначение «к дозору, приему и отдаче всякого ружья» специалистов западноевропейского происхождения было связано с тем, что именно из Западной Европы в Россию XVII в. ввозилась большая часть строевого оружия.

Как свидетельствуют источники, через ведомство оружничего во второй половине XVII в. проходила закупка за рубежом значительной части необходимого русскому войску оружия и снаряжения. В частности, в начале 1660-х гг. оружничим Богданом Матвеевичем Хитрово был заключен ряд крупных контрактов с голландскими предпринимателями Иваном Фансведеном и Андреем Свеленгреблем на поставку в Россию десятков тысяч единиц стрелкового оружия: «мушкетов с банделерами, карабинов с перевезьми, пистолетов с ольстрами», а также пушек, «лат рейтарских и солдацких», «спис» (пехотных пик), протазанов, алебард и пр. Среди различных предметов воинского назначения присутствовали «100 дудок деревянных, всякая дудка по 3 алтына 2 деньги» (инструменты для военной музыки, флейты), а также «8 ухватов всякой ухват по рублю по 16 алтын по 4 деньги» - редкие образцы нелетального оружия, 
«чем человека ухватить» $[8$, л. $1-23 ; 9$, л. $1-$ $30 ; 10$, л. $6 ; 11$, л. $1-3 ; 12$, л. $2 ; 13$, л. $1-2 ; 14$, л. 1; 15, л.1 ]. (В Оружейной палате в 1686/87 гг. хранилось «Сорок восмь ухватов железные, деревья ясеневые») [45, л. 132]. Общее число огнестрельного оружия, ввезенного в Московское государство Х. Севеленгреблем и Й. ван Сведенном в 1659-1662 гг., существенно превышало 100 тысяч единиц [2, с. 177-179].

Помимо Оружейной палаты в ведении оружничего находился приказ Ствольного дела (или Ствольный приказ), основная задача которого состояла в производстве строевого огнестрельного оружия. Среди направлений деятельности Ствольного приказа обращает на себя внимание работа по созданию так называемых «зависных (или завесных) казачьих» пищалей. Наиболее ранние сведения об изготовлении в приказе Ствольного дела «пищалей стрелецких винтованных с русскими замками и пищалей казачьих завесных с казачьими замками» относятся к середине XVII столетия [1, с. 143].

Речь идет, предположительно, о применявшихся в русской кавалерии ружьях с длинным гладким стволом небольшого калибра, обеспечивавшим возможность прицельного огня на больших дистанциях. В документах Оружейного приказа этот тип оружия назывался «пищали завесные казачьи гладкие». По мнению исследователя А.Н. Чубинского, происхождение этого типа восходит к восточным образцам [49, с. 136].

Во второй половине столетия оружие такого типа было весьма популярно при русском дворе. Мастера Оружейной палаты получали заказы на изготовление «пищалей, стволы длинные гладкие на турское дело». Пищали этого типа фигурируют в составе оружия поднесенного на Пасху царям Алексею Михайловичу и Федору Алексеевичу в 1663 , 1669, 1674, 1677 и 1681 годах. (Росписи «пасхальных подносных дел» сохранились не за все годы). Речь шла явно о парадном, украшенном оружии, ряд пищалей имели стволы, украшенные резьбой, золочением и серебрением, некоторые «красного железа» (из дамасской стали), деревянные части ружей инкрустировались перламутром и костью[ 19, л. $16 ; 20$, л. 23; 21, л. $5 ; 22$, л. $9 ; 23$, л. 5; 24, л. 1].

Строевые «зависные казачьи пищали» показали высокую боевую эффективность во время Северной войны, позволяя поражать противника с дистанций, превышающих предельную дальность ответного огня вражеских мушкетов. Примечательно, что шведский офицер, описывавший действия русских кавалеристов, был убежден, что ружья - «турки», применявшиеся казаками, были нарезными. Очевидно, шведу было трудно поверить, что прицельный огонь на столь значительные дистанции возможен из оружия с гладким стволом [50, с. 22].

Вероятно, изготовление стволов «завесных казачьих пищалей» представляло собой задачу повышенной технической сложности и вместе с тем относилось к разряду приоритетных. Так или иначе, в 1680-х гг. нескольким группам мастеров Оружейной палаты посменно велено было быть «у дела зависных пищалей в Ствольном приказе» [26, л. 13]. Работы велись на принадлежащем Ствольному приказу Бархатном дворе у южной стены Московского Кремля.

В мае 1681 г. царю Федору Алексеевичу били челом о жаловании «Оружейной палаты ствольного дела мастеры Григорий Вяткин с товарыши восмь человек», писали: «...работаем мы холопи твои на Бархатном дворе ствольного дела у правки другой год» $[25$, л. 1]. Около двух лет «первый мастер» Оружейной палаты Григорий Вяткин с товарищами трудился в Ствольном приказе «у досмотру, у правки и у отделки завесных пищалей», пока в 1682 г. его не сменил сын Афонасий, стоявший на втором месте в иерархии оружейников ведомства [27, л. 1-3]. Насколько можно понять, функции мастеров Оружейной палаты сводились к контролю качества и исправлению выявленных недостатков у сделанных мастерами Ствольного приказа «длинных гладких стволов».

В середине столетия мастера Оружейной палаты выступали в воинские походы лишь вместе с государем, сопровождая царскую походную Оружейную казну. Группы мастеров и служащих Оружейного приказа, состоявшие из оружейников разных специальностей, самопальных стрелков и сторожей, в 16541656 гг. побывали с царем Алексеем Михайловичем в Смоленском, Виленском и Рижском походах [5, с. 122-143].

Однако в последней четверти столетия ситуация существенно изменилась. Впервые 


\section{ОТЕЧЕСТВЕННАЯ ИСТОРИЯ}

специалисты придворной мастерской были направлены в войска в качестве армейских оружейников во время Крымских походов [28, л. 1-5]. В царствование Петра Алексеевича Оружейная палата в значительной степени утрачивает свое значение как придворная мастерская, все более ориентируя свою деятельность на удовлетворение потребностей действующей армии.

В 1695-1696 гг. «для государевой службы - оружейной починки» под Азов из Оружейной палаты были высланы двое подьячих, по четыре мастера ствольного, станочного и замочного дела, а также оклейщик и чищельник [29, л. 1-5]. Оружейники придворной мастерской рассылались по городам, где имелись значительные арсеналы и существовала потребность в оружейных мастерах. Документы содержат упоминания о посылке придворных оружейников и ряда мастеров других специальностей в Ахтырку (ныне город Сумской области на Украине) «к ружейной починке», в Симбирск «к горелому ружью к починке к ствольному делу», а также в города Воронеж, Самару, Белгород, Псков [17, л. $1-3 ; 18$, л. $1 ; 30$, л. $1 ; 46$, л. $1-3$ об.]. В 1704 г. семь мастеров Оружейной палаты для исправления оружия были отправлены в Шлиссельбург [6, с. 167].

В 1699 г. в деятельности Оружейной палаты происходит еще одно важное изменение. Из дотационного учреждения, которым она была на протяжении всего своего существования, придворная оружейная мастерская превращается в мощный источник доходов для казны. Перемены были связаны с осуществлением проекта Алексея Курбатова о вводе в употребление в России гербовой бумаги. Производство «клейменой бумаги» было налажено в Оружейной палате, а сам А.А. Курбатов стал ее дьяком. Обладая значительными финансовыми возможностями, оружейное ведомство активно выступало в роли заказчика, распределяя среди частных подрядчиков многочисленные задания на изготовление строевого оружия и снаряжения для русских войск. Московскими ремесленниками раздаются масштабные заказы на изготовление в Оружейную палату лядунок (патронных сумок), перевязей, поясов, багинетов к солдатским фузеям для «новоприбранных полков» и пр. [31, л. 1-3; 32, л. 1-2; 33, л. 1; 34, л. 1-2; 35 , л. $1 ; 39$, л. $1-5 ; 40$, л. $1-2 ; 41$, л. $1-4 ; 42$, л. 1-2]. Важные сведения о кадровом составе и направлениях деятельности Оружейной палаты в первой четверти XVIII в. содержат исследования Е.И. Смирновой и М.К. Павлович [6, с. 165-175; 48, с. 95-100].

Как и ранее, в начале XVIII столетия администрацией Оружейной палаты заключались сделки с иностранными поставщиками на ввоз в Россию партий оружия. Так, в августе 1700 г. по приказу возглавлявшего ведомство Федора Алексеевича Головина было велено принять в Архангельске закупленную у иноземца Бранта относительно небольшую партию оружия - 4000 фузей. Для проверки соответствия заказа должностному лицу, отправленному принимать оружие из Оружейной палаты, была отослана «заклейменная образцовая пищаль» $[36$, л. 1-5]. Все принятые фузеи должны были пройти огневые испытания - так называемый «прострел» [37, л. 12]. Вероятно, результаты сочли вполне удовлетворительными.

В следующем 1701 г. в Оружейной палате был заключен очередной договор: «Любека города торговый иноземец Адам Петров сын Брант уговорился поставить... дватцать тысяч фузей самого доброго заморского мастерства». Для расчета с иноземцем в Амстердам русскому послу Андрею Артамоновичу Матвееву были отправлены платежные векселя [38, л. 1-3].

Что же касается штатных мастеров Оружейной палаты, то практически все специалисты кузнечных и столярных специальностей в этот период трудились над изготовлением строевого оружия на Бархатном дворе. Согласно росписи 1701 г. «у всяких государевых оружейных дел» в приказе Ствольного дела «беспрестанно» работало 39 мастеров Оружейной палаты [16, л. 1-3; 43, 1-6]. Некоторые мастера Оружейной палаты получали особые задания, связанные с попытками реорганизации оружейного дела в русских городах. Так, в 1702 г. в Устюжне Железнопольской было велено провести опыт по изготовлению фузейных стволов из местного железа [44, л. 1]. К рутинным видам деятельности относились ремонт и чистка хранящегося в Палате ору- 
жия. Причем, в начале XVIII в. к этим работам привлекались и пленные шведы [47, л. 37 об.].

Таким образом, мы видим, что Оружейная палата играла важную роль в материальном снабжении вооруженных сил. Причем с середины столетия деятельность ведомства (административная, производственная, финансовая) все в большей степени ориентировалась на удовлетворение потребностей русской армии в оружии, снаряжении и мастерах-оружейниках.

\section{ПРИМЕЧАНИЕ}

${ }^{1}$ В данной работе не рассматривается такой важный и специфический вопрос, как создание иконописцами и живописцами Оружейной палаты знамен для русского войска.

\section{СПИСОК ЛИТЕРАТУРЫ}

1. Арсеньев, Ю. Оружейный приказ при царе Михаиле Федоровиче. Материалы извлеченные из архива Оружейной палаты / Ю. Арсеньев // Вестник археологии и истории издаваемый имп. Археологическим институтом. - СПб. : Типография П.П. Сойкина, 1904. - Вып. 15. - С. 131-198.

2. Велувенкамп, Я. В. Архангельск / Я. В. Велувенкамп. - М. : РОССПЭН, 2006. -311 с.

3. Комаров, И. А. Вступительная статья / И. А. Комаров // Государева Оружейная палата. СПб. : Атлант 2002. - С. 8-37.

4. Ларченко, М. Н. Перечневая роспись Оружейной казны царя Алексея Михайловича // Археографический ежегодник за 1971 г. / М. Н. Ларченко. - М. : Наука, 1972. - С. 173-181.

5. Орленко, С. П. Оружейный мастер Григорий Никитич Вяткин / С. П. Орленко // Война и Оружие. Новые исследования и материалы. - СПб. : ВИМАИВиВС, 2011. - Ч. II. - С. 122-143.

6. Павлович, М. К. Мастера оружейного дела в Московском Кремле в XVIII веке / М. К. Павлович // Война и оружие. Новые исследования и материалы. - СПб. : ВИМАИВиВС, 2011. - Ч. II. C. $165-175$.

7. Российский государственный архив Древних актов (далее - РГАДА). - Ф. 396. - Оп. 1. Д. 3593. Роспись государевой оружейной казны. 1647 г.

8. РГАДА. - Ф. 396. - Оп. 1. - Д. 7129. О выдаче голландцу Ивану Фансведену с товарищами за поставку в Оружейную палату вещей.
9. РГАДА. - Ф. 396. - Оп. 1. - Д. 7279. О даче из Оружейной палаты иноземцам Ивану Фансведену и Андрею Артемьеву и Якову Яковлеву за разные ружья.

10. РГАДА. - Ф. 396. - Оп. 1. - Д. 7550. Челобитная И. Фансведена и А. Свеленгребля о невзятии с него пошлин в Архангельске за поставленное в казну оружие.

11. РГАДА. - Ф. 396. - Оп. 1. - Д. 7709. Доклад сколько оружия поставили Фонсведен и Артемьев и сколько понадобилось подвод...

12. РГАДА. - Ф. 396. - Оп. 1. - Д. 7711. Выписка сколько оружия взято в 168 г. 15 февраля у Ивана Фансведена и что вместо денег за него было велено дать.

13. РГАДА. - Ф. 396. - ОП. 1. - Д. 7839. Оружейная палата о выдаче денег иноземцу Андрею Свеленгреблю за ружье.

14. РГАДА. - Ф. 396. - Оп. 1. - Д. 7890. Оружейная палата о выдаче денег иноземцу Андрею Свеленгреблю за ружье.

15. РГАДА. - Ф. 396. - Оп. 1. - Д. 8088. Челобитная И. Фансведена и А. Свеленгребля о невзыскании с поставленного ими ружья таможенных пошлин.

16. РГАДА. - Ф. 396. - Оп. 1. - Д. 8183. Челобитная мастера Афанасия Вяткина с товарищами...

17. РГАДА. - Ф. 396. - Оп. 1. - Д. 8510. Челобитные Оружейной палаты ствольного дела мастеров Романа Анисимова Камаева и Куприяна Осипова о назначении им жалования.

18. РГАДА. - Ф. 396. - ОП. 1. - Д. 8616. О даче жалования Оружейной палаты мастерам и станочникам которые посланы во Псков для ружейной починки.

19. РГАДА. - Ф. 396. - Оп. 1. - Д. 8725. Столп, а в нем роспись мастерам и оружию сделанному государю в поднос на Пасху.

20. РГАДА. - Ф. 396. - ОП. 1. - Д. 11295. О выдаче денег на всякие покупки...

21. РГАДА. - Ф. 396. - Оп. 1. - Д. 12267. Роспись подносных дел Оружейной палаты царю Алексею Михайловичу на Пасху.

22. РГАДА. - Ф. 396. - Оп. 1. - Д. 14946. О поднесении к Пасхе разных вещей сделанных в Оружейной палате по наряду.

23. РГАДА. - Ф. 396. - Оп. 1. - Д. 16897. О сделанных в Оружейной палате к дню Св. Пасхи разных вещах к подносу царю по наряду знамени, пищали, пистоли.

24. РГАДА. - Ф. 396. - ОП. 1. - Д. 19919. Об отпуске кости для сделания в поднос к Пасхе вещей в Оружейную палату.

25. РГАДА. - Ф. 396. - Оп. 1. - Д. 20003. Челобитная Григория Вяткина с товарищами о пожаловании... 
26. РГАДА. - Ф. 396. - Оп. 1. - Д. 20276. Об изготовлении к Пасхе мастерами Оружейной палаты подносных вещей по приказу боярина оружничего Ивана Максимовича Языкова с описанием необходимых средств.

27. РГАДА. - Ф. 396. - Оп. 1. - Д. 21937. Челобитная Григория и Афанасия Вяткиных о пожаловании...

28. РГАДА. - Ф. 396. - Оп. 1. - Д. 26315. О посылке в Крымский поход в полки мастеров для починки ружья.

29. РГАДА. - Ф. 396. - Оп. 1. - Д. 32089. О бытии для оружейной починки на службе под Азовом подьячим и мастеровым людям.

30. РГАДА. - Ф. 396. - Оп. 1. - Д. 33157. О посылке 10 оружейных мастеров Оружейной палаты в Белгород для починки ружья.

31. РГАДА. - Ф. 396. - Оп. 1. - Д. 33936. О сделании в Оружейную палату в новоприбраные солдацкие полки 1000 сум с лядунками, перевезьми и багинетных поясов.

32. РГАДА. - Ф. 396. - Оп. 1. - Д. 34540. О сделании в Оружейную палату садовой слободы Петром Федоровым на дачу новоприборным солдатам 6000 багинетных полос.

33. РГАДА. - Ф. 396. - Оп. 1. - Д. 34543. Поручная запись по садовнике по Петре Федорове в том, чтобы сделать ему в Оружейную палату...

34. РГАДА. - Ф. 396. - Оп. 1. - Д. 34552. О подряде Конюшенного приказа строчного дела мастера Данилы Ильина Третьякова о сделании в Оружейную палату новоприбраным солдатам 5000 багинетных полос.

35. РГАДА. - Ф. 396. - Оп. 1. - Д. 34559. Поручная запись Конюшенного приказа строчного дела по мастере Даниде Ильину Третьякову о сделании...

36. РГАДА. -Ф. 396.-Оп. 1.-Д. 34645. О приеме в Архангельске 4000 фузей иностранной работы.

37. РГАДА. - Ф. 396. - Оп. 1. - Д. 34940. О простреле в Оружейной палате присланых от иноземца Бранта 4000 фузей.

38. РГАДА. - Ф. 396. - Оп. 1. - Д. 35254. О поставке иноземцу А. Брандту в Амстердам 20000 фузей и о даче за оные денег.

39. РГАДА. - Ф. 396. - Оп. 1. - Д. 35640. Память Преображенского полка солдату Ивану Несмеянову... о сделании 500 кривых багинетов и присадке к фузеям.

40. РГАДА. - Ф. 396. - Оп. 1. - Д. 35641. О сделании кривых багинетов и присадке их к фузеям.

41. РГАДА. - Ф. 396. - Оп. 1. - Д. 35644. Уговор Огородной слободы Ивана Петрова о сделании 500 багинетов кривых с ножнами.

42. РГАДА. - Ф. 396. - Оп. 1. - Д. 35650. Поручная запись по оружейном мастере Андрее Килты- кееве о том, что сделать ему и поставить в Оружейную палату 500 багинетов...

43. РГАДА. - Ф. 396. - Оп. 1. - Д. 35788. Челобитная Афанасия Вяткина с товарищами о даче мастерам Оружейной палаты жалования за 702 г.

44. РГАДА. - Ф. 396. - Оп. 1. - Д. 36124. О посылке из Оружейной палаты ствольного мастера в Устюжну Железнополькую для пробного изготовления из местного железа фузей по немецким и тульским образцам.

45. РГАДА. - Ф. 396. - Оп. 2. - Д. 936. Переписная книга Оружейной и всякой царской казне и красок что в Оружейной палате, в Большой казне, и в прочих палатах... 1687 г.

46. РГАДА. - Ф. 396. - Оп. 2. - Д. 967. Окладная расходная книга по выдаче жалования... 7204 г. (1695-1696 гт.).

47. РГАДА. - Ф. 396. - Оп. 2. - Д. 974. Приходная и расходная книги денежной казне 1711 г.

48. Смирнова, Е. И. К вопросу о составе и денежном обеспечении мастеров Оружейной и Мастерской палаты в 1711-1730 годах / Е. И. Смирнова // Материалы и исследования. Музеи Московского Кремля. - М. : Искусство, 1989. - Вып. VI. C. $95-100$.

49. Чубинский, А. Н. Казачьи пищали в собрании Музеев Московского Кремля / А. Н. Чубинский // Материалы и исследования. Музеи Московского Кремля. - М. : Первый издательско-полиграфический холдинг, 2012. - Вып. XXI. - С. 122 - 141.

50. Энглунд, П. Полтава. Рассказ о гибели одной армии / П. Энглунд. - М. : Новое книжное обозрение, 1995. - 288 c.

\section{REFERENCES}

1. Arsenyev Yu. Oruzheynyy prikaz pri tsare Mikhaile Fedoroviche. Materialy izvlechennye iz arkhiva Oruzheynoy palaty [Armory Chamber in the Reign of Mikhail Feodorovich. Sources From Archive of the Armoury]. Vestnik arkheologii $i$ istorii izdavaemyy imp. Arkheologicheskim institutom, 1904, iss. 15, pp. 131-198.

2. Veluvenkamp Ya.V. Arkhangelsk [Arkhangelsk]. Moscow, ROSSPEN Publ., 2006. 311 p.

3. Komarov I.A. Vstupitelnaya statya [Introductory Article]. Gosudareva Oruzheynaya palata [Armory Chamber of the Russian Tsars]. Saint Petersburg, Atlant Publ., 2002, pp. 8-37.

4. Larchenko M.N. Perechnevaya rospis Oruzheynoy kazny tsarya Alekseya Mikhaylovicha [Inventory of the Armory of Tsar Alexey Mikhailovich]. Arkheograficheskiy ezhegodnik za $1971 \mathrm{~g}$. [Archaeography Yearbook for 1971]. Moscow, Nauka Publ., 1972, pp. 173-181. 
5. Orlenko S.P. Oruzheynyy master Grigoriy Nikitich Vyatkin [Gunsmith Grigoriy N. Vyatkin]. Voyna i Oruzhie. Novye issledovaniya i materialy [War and Weapon. New Research and Materials]. Saint Petersburg, VIMAIViVS Publ., 2011, part 2, pp. 122-143.

6. Pavlovich M.K. Mastera oruzheynogo dela v Moskovskom Kremle v XVIII veke [Gunsmiths in Moscow Kremlin in the 18th Century]. Voyna i Oruzhie. Novye issledovaniya i materialy [War and Weapon. New Research and Materials]. Saint Petersburg, VIMAIViVS Publ., 2011, part 2, pp. 165-175.

7. Rossiyskiy gosudarstvennyy arkhiv drevnikh aktov [Russian State Archive of Ancient Acts], F. 396, Op. 1, D. 3593. Inventory of Sovereign Armory Treasury. 1647.

8. RGADA [Russian State Archive of Ancient Acts], F. 396, Op. 1, D. 7129. On the Issue of the Dutchman Ivan Fansveden and His Teammates for the Supply of the Armory Things.

9. RGADA [Russian State Archive of Ancient Acts], F. 396, Op. 1, D. 7279. About the Delivery From the Armory Foreigners Ivan Fansveden and Andrey Artemyev and Yakov Yakovlev of Various Guns.

10. $R G A D A$ [Russian State Archive of Ancient Acts], F. 396, Op. 1, D. 7550. Petition of J. Svelengrebl and A. Fansveden on Non-Capture of Weapon Fees Delivered to the Treasury in Arkhangelsk.

11. RGADA [Russian State Archive of Ancient Acts], F. 396, Op. 1, D. 7709. Report on How Many Weapons Were Supplied by Fonsveden and How Many Carts Were Required.

12. RGADA [Russian State Archive of Ancient Acts], F. 396, Op. 1, D. 7711. Extract on How Many Weapons Were Taken on February 15, 168 From Ivan Fansveden and What Was Commanded to Give Instead of Money.

13. RGADA [Russian State Archive of Ancient Acts], F. 396, Op. 1, D. 7839. Armory on Granting Money for the Stranger Andrew Svelengrebl for Gun.

14. $R G A D A$ [Russian State Archive of Ancient Acts], F. 396, Op. 1, D. 7890. Armory on Granting Money for the Stranger Andrew Svelengrebl for Gun.

15. RGADA [Russian State Archive of Ancient Acts], F. 396, Op. 1, D. 8088. Petition of I. Fansveden and A. Svelengrebl on Non-Recovery of Fees for the Gun Delivered.

16. RGADA [Russian State Archive of Ancient Acts], F. 396, Op. 1, D. 8183. The Petition of Master Athanasius Vyatkin and His Comrades.

17. RGADA [Russian State Archive of Ancient Acts], F. 396, Op. 1, D. 8510. Petitions of Armory Barrel Business Masters Roman Anisimov Kamaev and Kupriyan Osipov on the Appointment of Their Salaries.

18. RGADA [Russian State Archive of Ancient Acts], F. 396, Op. 1, D. 8616. On the Appintment of
Salary to Armory Craftsmen and Machinists Who Are Sent to Pskov to Repair a Rifle.

19. RGADA [Russian State Archive of Ancient Acts], F. 396, Op. 1, D. 8725. Pillar Painted by a Master of Weapons for the Emperor on the Easter tray.

20. RGADA [Russian State Archive of Ancient Acts], F. 396, Op. 1, D. 11295. On the Issue of Money for Any Purchase.

21. RGADA [Russian State Archive of Ancient Acts], F. 396, Op. 1, D. 12267. Painting Ester Trays for Tsar Alexey Mikhailovich.

22. RGADA [Russian State Archive of Ancient Acts], F. 396, Op. 1, D. 14946. On Easter Presentation of Different Things Made in the Armory.

23. RGADA [Russian State Archive of Ancient Acts], F. 396, Op. 1, D. 16897. About Different Things Made in the Armory to the Day of St. Easter for the King Along the Flag, Food, Pistols.

24. RGADA [Russian State Archive of Ancient Acts], F. 396, Op. 1, D. 19919. On Holiday for Creating Items to the Armory for Easter.

25. RGADA [Russian State Archive of Ancient Acts], F. 396, Op. 1, D. 20003. The Petition of Grigory Vyatkin and His Comrades on the award.

26. RGADA [Russian State Archive of Ancient Acts], F. 396, Op. 1, D. 20276. On the Manufacturing of Easter Presents by the Armory Masters be the Order of Ivana Yazykov Boyar with the Description of the Necessary Funds.

27. RGADA [Russian State Archive of Ancient Acts], F. 396, Op. 1, D. 21937. The Petition of Gregory anf Athanasius Vyatkin on Award.

28. RGADA [Russian State Archive of Ancient Acts], F. 396, Op. 1, D. 26315. On Sending Craftsmen to Repair the Gun in the Crimean Campaign.

29. RGADA [Russian State Archive of Ancient Acts], F. 396, Op. 1, D. 32089. On Being an Assistant to Repair Weapon in the Service Under Azov.

30. RGADA [Russian State Archive of Ancient Acts], F. 396, Op. 1, D. 33157. About Sending 10 Armory Gunsmiths in Belgorod to Repair the Gun.

31. RGADA [Russian State Archive of Ancient Acts], F. 396, Op. 1, D. 33936. About Making 1000 Pouches and Belts for the Armory.

32. RGADA [Russian State Archive of Ancient Acts], F. 396, Op. 1, D. 34540. About Making 6,000 Bayonet Bands for Armory Soldiers.

33. RGADA [Russian State Archive of Ancient Acts], F. 396, Op. 1, D. 34543. Handrails Recording on Gardener Petr Fedorov.

34. RGADA [Russian State Archive of Ancient Acts], F. 396, Op. 1, D. 34552. About Contract of Danila Tretyakov from Horse Commandment on Making 5,000 Bayonet Bands for Newly Arrived Soldiers.

35. RGADA [Russian State Archive of Ancient Acts], F. 396, Op. 1, D. 34559. Handrails Record of Horse Commandment on Craftsman Danila Tretyakov. 
36. RGADA [Russian State Archive of Ancient Acts], F. 396, Op. 1, D. 34645. About Reception of 4,000 Fusils of Foreign Origin in Arkhangelsk.

37. RGADA [Russian State Archive of Ancient Acts], F. 396, Op. 1, D. 34940. Shooting-through the 4,000 Foreign Fusils Sent by Brant.

38. RGADA [Russian State Archive of Ancient Acts], F. 396, Op. 1, D. 35254. About Delivery of 20,000 Fusils to Foreigner A. Brandt in Amsterdam.

39. RGADA [Russian State Archive of Ancient Acts], F. 396, Op. 1, D. 35640. Memory of the Preobrazhensky Regiment to Soldier Ivan Nesmeyanov... on the Creation of 500 Curved Bayonets.

40. RGADA [Russian State Archive of Ancient Acts], F. 396, Op. 1, D. 35641. On the Creation of Curved Bayonets and Attaching Them to Fusils.

41. RGADA [Russian State Archive of Ancient Acts], F. 396, Op. 1, D. 35644. Agreement of Ogorodnaya Settlement of Ivan Petrov on the Establishment of 500 Curved Bayonets with Sheaths.

42. RGADA [Russian State Archive of Ancient Acts], F. 396, Op. 1, D. 35650. Handrails Recording on Gunsmith Andrey Kiltykeev Who Must Make 500 Bayonets and Deliver Them to the Armory.

43. RGADA [Russian State Archive of Ancient Acts], F. 396, Op. 1, D. 35788. The Petition of Athanasius Vyatkin With Teammates on Giving Armory Masters Salary for 702 Year.

44. RGADA [Russian State Archive of Ancient Acts], F. 396, Op. 1, D. 36124. On Sending the Armory Barrel Master to Ustyuzhna Zheleznopolkaya for Trial
Manufacture of Fusils from Local Iron on German and Tula Samples.

45. RGADA [Russian State Archive of Ancient Acts], F. 396, Op. 2, D. 936. Armory Census Book and All the Royal Treasury and Paints in the Armory Grand Treasury and Other Chambers... 1687.

46. RGADA [Russian State Archive of Ancient Acts], F. 396, Op. 2, D. 967. Invoice Book Expenditure for Issuing Salary ... 7204 (1695-1696).

47. RGADA [Russian State Archive of Ancient Acts], F. 396 Op. 2 D. 974. Incoming and Outgoing Books of Monetary Treasury 1711.

48. Smirnova E.I. K voprosu o sostave i denezhnom obespechenii masterov Oruzheynoy i Masterskoy palaty v 1711-1730 godakh [To the Question About Personnel and Payroll of Masters of the Armory and Craft Chambers in 1711-1730]. Materialy $i$ issledovaniya. Muzei Moskovskogo Kremlya [Materials and Research. Moscow Kremlin Museums]. Moscow, Iskusstvo Publ., 1989, iss. 6, pp. 95-100.

49. ChubinskiyA.N. Kazachyi pishchali v sobranii Muzeev Moskovskogo Kremlya [Cossack Guns in the Collection of Moscow Kremlin Museums]. Materialy $i$ issledovaniya. Muzei Moskovskogo Kremlya [Materials and Research. Moscow Kremlin Museums]. Moscow, Pervyy izdatelsko-poligraficheskiy kholding, 2012, iss. 21, pp. 122-141.

50. Englund P. Poltava. Rasskaz o gibeli odnoy armii [Poltava. The Story About the Downfall of One Army]. Moscow, Novoe knizhnoe obozrenie Publ., $1995.288 \mathrm{p}$. 